\title{
An in Vivo Approach for Globally Estimating the Drug Flow between Blood and Tissue for Nafamostat Mesilate: the Main Hydrolysis Site Determination in Human
}

\author{
Yan-Guang CAO," Yuan-Cheng ChEN,, Kun HaO, Ming Zhang, and Xiao-Quan LiU* \\ Key Laboratory of Drug Metabolism \& Pharmacokinetics, China Pharmaceutical University; Nanjing 210009, P. R. China. \\ Received February 20, 2008; accepted August 19, 2008; published online August 20, 2008
}

\begin{abstract}
Nafamostat mesilate, an ester drug with extensive hydrolysis in vivo, exhibits species difference in the relative contribution for its hydrolysis in blood and tissues. For the rat, the main hydrolysis site may be blood and human may be tissue (mainly by liver). The paper gave in vivo evidence that human tissue may give more contribution for its hydrolysis. In the initial phase of drug administration, the drug accumulating level in tissue was low; the efflux fraction from tissue into blood can be ignorable comparing with the drug influx into tissue. Based on urine and plasma metabolite analysis, we concluded that in the initial phase almost all the drug hydrolysis in blood was excreted into urine. Then according to the initial urine metabolite analysis, we can estimate the drug hydrolysis rate in blood. The rate of drug diffusion from blood into tissues can be deduced based on the mass balance analysis of the initial blood drug. With the estimated rate constants, the drug efflux from tissues into blood was calculated according to equation: $O F_{\mathrm{T}-\mathrm{B}}$ (efflux from tissues) $=O F_{\mathrm{B}-\mathrm{U}}$ (blood hydrolysis fraction) $+O F_{\mathrm{B}-\mathrm{T}}$ (influx into tissues) $-D_{B}$ (hydrolysis in blood). The net flow (influent flux minus effluent flux) represented the drug hydrolysis fraction in tissue. As the result indicated, in human about $20 \%$ drug administrated was hydrolyzed in blood and nearly $80 \%$ in tissues. The relative hydrolysis fraction indicated that the main hydrolysis site in human body may locate in tissue, which was different to rats.
\end{abstract}

Key words nafamostat mesilate; in vivo approach; hydrolysis site; drug flow; globally estimating

Nafamostat mesilate, a strong synthetic protease inhibitor, is mainly used for treatments of DIC (disseminated intravascular coagulation) and acute pancreatitis, also as an anticoagulant in extracorporeal circulation. ${ }^{1)}$ Besides, nafamostat exhibits wide pharmacological activities and many of them have been applied clinically, including anti-tumor and liver protection activities. ${ }^{2,3)}$ Nafamostat, which is an ester conjugate of 6-amidino-2-naphthol (AN) and $p$-guanidinobenzoic acid ( $p$-GBA), can rapidly hydrolyze into AN and $p$-GBA in vivo and the enzymes responsible for nafamostat hydrolysis distribute all over the body, including the arylesterases in blood, carboxylesterases by liver microsome and long-chain acyl-CoA hydrolase by liver cytosol. ${ }^{4,5)}$ Because the ester group is the essential and active group, the rate of ester hydrolysis may affect the duration of its pharmacological activity. Subsequent hydrolysis, the two metabolites can then conjugate with glucuronide. Major metabolites of nafamostat in rats were $\mathrm{AN}$, its glucuronide conjugate and the unchanged form of nafamostat was less detectable in urine and feces of rats. ${ }^{6)}$ These findings suggested that nafamostat might be hydrolyzed mainly by rat blood esterase and, to a minor extent, by tissue esterase (mainly refer to liver). In humans, a blood half-life of nafamostat elimination was approximately $23 \mathrm{~min}$ and longer than rats, ${ }^{7)}$ which can be explained by higher esterase activities of rat blood. ${ }^{8)}$ Accordingly, the contribution of human tissue to the nafamostat hydrolysis would be larger than that of rat, which suggests that, in addition to the blood, tissue esterase may be other important metabolic sites of nafamostat. According to the species differences, some researchers have conducted the nafamostat metabolism in vitro experiments and compared the relative activity of liver and blood esterase for nafamostat hydrolysis. ${ }^{4)}$ However, the drug exposure level and esterase abundance in different parts of the body may complicate the in vivo condition. Up to now, there is still no in vivo evidence in human that indicates the contribution of tissues for nafamostat hydrolysis is larger than blood. ${ }^{4)}$ In our research, according to the tissues distribution level analysis, we tried to globally estimate the drug hydrolysis fraction in tissue and blood.

Nafamostat can rapidly and extensively distribute into various tissues and the concentration in several high blood-perfusion tissues exceeds blood many times. ${ }^{\text {) }}$ For this kind of drug, due to the high tissue accumulation and hydrolysis level, if without sampling in tissue compartment, it is hard to predict the drug tissue level just with plasma concentration data. But in clinical study, it is difficult to direct sample in tissues. Some researches predicted the tissue concentration level with the in vitro organ perfusion data and physiological parameters. ${ }^{9)}$ However, the physiological parameters often show high individual variability, the physiological-based models often exhibit great discrepancy. ${ }^{10)}$ In our paper, according to nafamostat pharmacokinetic behaviors, such as only minor eliminating as parent drug and mainly excreting through urine, rapidly and extensively distributing into tissues, we developed an approach that can globally estimated drug flow between tissue and blood. The net flow between blood and tissue represented the drug hydrolysis fraction by tissue esterase.

\section{MATERIALS AND METHODS}

Subjects Nine healthy volunteers were recruited, and written informed consent was obtained from each subject prior to study procedures. Subjects between 20 and 30 years of age were allowed to enroll in the study with the exception of existing hepatic impairment (confirmed by a previous liver biopsy specimen or liver spleen scan). Subjects were excluded if they had a history (within the past 12 months) of al- 
cohol and/or drug abuse, had a positive drug or alcohol screening result at the screening visit or on day -1 . The experiment was conducted with the permission from the local Ethics Committee.

Experiment Design Each subject was given $20 \mathrm{mg}$ nafamostat mesilate via intravenous drip infusion at constant rate within $120 \mathrm{~min}$. During drug infusion, about $3 \mathrm{ml}$ blood samples were collected at $0,30,60,120 \mathrm{~min}$ and after infusion samples were collected at $0,2,5,10,30,60,120,180$, $240,360 \mathrm{~min}$ through an indwelling cathether. The urine was also collected in the initial infusion of $2 \mathrm{~h}$.

Analytical Method Blood samples were centrifuged immediately for plasma collection. Plasma concentrations of nafamostat and its main metabolite $\mathrm{AN}$ were quantified by the validated LC-ESI-MS method based on solid phase extraction, which has been described in our other paper. ${ }^{11)}$ Briefly, $1 \mathrm{ml}$ spiked plasma samples were extracted by Solid Phase Extraction (SPE) on a $\mathrm{C}_{18}$ cartridge (Sep-Pak Cartridges, Waters, U.S.A.) using the following procedure: (1) Conditioning with $1 \mathrm{ml}$ methanol followed by $1 \mathrm{ml}$ of watermethanol $95: 5(\mathrm{v} / \mathrm{v})$; (2) loading the plasma sample diluted with $1 \mathrm{ml}(1 / 1, \mathrm{v} / \mathrm{v}) \mathrm{pH} 7.4$ PBS $(0.1 \mathrm{M})$ containing $1 \mu \mathrm{g} / \mathrm{ml}$ of internal standard (I.S.); (3) clean-up in two steps: $1 \mathrm{ml} \mathrm{pH}$ 5.0 PBS $(0.1 \mathrm{M})$, then $4 \mathrm{ml}$ purified water; (4) elution of analysts with $0.5 \mathrm{ml}$ acid methanol ( $1 \%$ formic acid, $\mathrm{v} / \mathrm{v})$. The HPLC procedure used a $\mathrm{C}_{18}$ column $(150 \mathrm{~mm} \times 3.0 \mathrm{~mm}, 2.0$ $\mu \mathrm{m})$ with the mobile phase of methanol-water-formic acid $(15: 85: 0.001, \mathrm{v} / \mathrm{v} / \mathrm{v})$ at a flow rate of $0.2 \mathrm{ml} / \mathrm{min}$. Analysis was carried out using selected ion monitoring (SIM) for specific $m / z 174.55$ for nafamostat $[\mathrm{M}+2 \mathrm{H}]^{2+}, 186.90$ for AN $[\mathrm{M}+\mathrm{H}]^{+}$and 172.05 for I.S. gabapentin $[\mathrm{M}+\mathrm{H}]^{+} .0 .2 \mathrm{ml}$ urine sample was prepared as the same procedure described above.

Approach Development Procedure Nafamostat is a drug with wide tissue distribution and extensively metabolism. It can be hydrolyzed into AN and $p$-GBA at many sites of the body. ${ }^{4)}$ The hydrolysis capacity in plasma is so large that the concentration in plasma is far below blood hydrolysis $K_{\mathrm{m}}$ (substrate concentration that can reach half of the hydrolysis velocity). ${ }^{4)}$ Besides rapid hydrolysis, the rate and extent of distribution into tissues is also so large that the system concentration cannot approach the distribution $K_{\mathrm{m}}$ (substrate concentration that can reach half of the maximum distribution velocity). That is to say, under plasma concentration level, both of the processes for blood drug elimination could be regarded as first order kinetics. The fate of drug after intravenous dripping infusion can be delineated as Fig. 1.

The model is described by the following differential equations during infusion:

$$
\begin{gathered}
\frac{d x_{1}}{d t}=k_{0}-k_{\mathrm{p}} x_{1}-k_{\mathrm{d}} x_{1}+k_{1} x_{2} \\
\frac{d x_{2}}{d t}=-k_{1} x_{2}-k_{\mathrm{T}} x_{2}+k_{\mathrm{d}} x_{1} \\
\frac{d x_{\mathrm{u}}}{d t}=k_{\mathrm{p}} x_{1}
\end{gathered}
$$

Where $x_{1}$ and $x_{2}$ represent drug amount in blood and tissue compartment, respectively. $x_{\mathrm{u}}$ represent compartment amount just from hydrolysis in blood. $k_{\mathrm{d}}$ and $k_{1}$ indicated rate constant of drug influx into and efflux from tissue, $k_{\mathrm{p}}$ means drug hydrolyzed rate constant in blood, $k_{0}$ infusion dripping

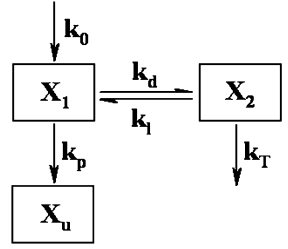

Fig. 1. A Schematic of a Two-Compartment Pharmacokinetic Model for Nafamostat Mesilate

Where $x_{1}$ and $x_{2}$ represent blood and tissues compartment, respectively. $x_{u}$ excretion compartment just from hydrolysis in blood. $k_{\mathrm{d}}$ drug influx into tissues rate constant, $k_{\mathrm{p}}$ and $k_{1}$ drug influx into and efflux from tissues rate constant. $k_{0}$ infusion dripping rate constant.

rate. According to high accumulation in tissue, ${ }^{6)}$ we hypothesized that in the initial period of drug infusion $(2 \mathrm{~h})$, the drug efflux from tissues into plasma (via $k_{1}$ ) was slow and can be neglected in comparison with the drug influx into tissue (via $k_{\mathrm{d}}$ ) and hydrolysis in blood (via $k_{\mathrm{p}}$ ). If not, the drug cannot accumulate so high in the tissues as previously reported. $\left.{ }^{6}\right)$ Thus in the initial phase of drug infusion we can simplify the Eqs. 1 to 4 as follows:

$$
\frac{d x_{1}}{d t}=k_{0}-k_{\mathrm{p}} x_{1}-k_{\mathrm{d}} x_{1}
$$

Where $k_{0}$ is the infusion rate, then we defined parameter $k_{\text {total }}$ as Eq. 5

$$
k_{\text {total }}=k_{\mathrm{d}}+k_{\mathrm{p}}
$$

Then the Eq. 4 can be transformed into Eq. 6 through Laplace transformation.

$$
c_{1}=\frac{k_{0}}{V_{1} \cdot k_{\text {total }}}\left(1-e^{-k_{\text {toat }} \cdot t}\right)
$$

Fitting the initial $c_{1}-t$ points according to Eq. 6, we can estimate the value of $V_{1}$ (volume of distribution) and $k_{\text {total }}$.

In the initial phase, the main metabolite AN was simultaneously determined in plasma samples. But the plasma concentration of AN was under lowest limit of quantification $(1.25 \mathrm{ng} / \mathrm{ml})$, which indicated that the AN system retention time is very short and nearly all the AN was excreted into urine in consistent with previous report. ${ }^{7)}$ The elucidation was properly in agreement with the urine sample analysis, where large amount of AN (mainly as free form) excreted in collected urine and nearly no parent drug was detected in urine, which has been described previously. ${ }^{7)}$ It was also hypothesized that free form of AN excreted in the initial period was mainly through $k_{\mathrm{p}}$ pathway. Thus, based on the initial excretion amount in urine we can calculate the blood hydrolysis rate $\left(k_{\mathrm{p}}\right)$ as the following Eqs. 7 and 8, which was from the integration of Eq. 3 from beginning to time $t$.

$$
\begin{aligned}
& \left.x_{\mathrm{u}}\right|_{0} ^{t}=k_{\mathrm{p}} \int_{0}^{t} c_{1} V_{1} d t \\
& k_{\mathrm{p}}=\frac{x_{\mathrm{u}(t)}}{A U C_{1(t)} \cdot V_{1}}
\end{aligned}
$$

According to Eq. 5, with the estimated $k_{\mathrm{p}}$ and $k_{\text {total }}$, the $k_{\mathrm{d}}$ can be calculated. The amount of hydrolysis in blood and influx into tissue can be estimated according to formula 9 and 10 , respectively. 
Table 1. Estimated Pharmacokinetic Parameters of 9 Healthy Volunteers after Intravenous Dripping Infusion of 20 mg Nafamostat Mesilate

\begin{tabular}{|c|c|c|c|c|c|c|c|c|c|c|c|}
\hline \multirow{2}{*}{ Parameters } & \multicolumn{9}{|c|}{ Subjects } & \multirow{2}{*}{ Mean } & \multirow{2}{*}{ S.D. } \\
\hline & 1 & 2 & 3 & 4 & 5 & 6 & 7 & 8 & 9 & & \\
\hline$A U C_{0-t}(\mathrm{ng} / \mathrm{ml} \cdot \mathrm{min})$ & 6072 & 3721 & 6317 & 3500 & 3612 & 1721 & 1578 & 1200 & 1702 & 3269 & 1921 \\
\hline$A U C_{0-\infty}(\mathrm{ng} / \mathrm{ml} \cdot \mathrm{min})$ & 7064 & 4782 & 6884 & 4287 & 4057 & 2496 & 2100 & 1863 & 2316 & 3983 & 1990 \\
\hline$C_{\max }(\mathrm{ng} / \mathrm{ml})$ & 50.88 & 30.73 & 65.41 & 34.2 & 43.9 & 33.21 & 33.35 & 25.11 & 46.79 & 40.40 & 12.53 \\
\hline$t_{1 / 2(\alpha)}(\min )$ & 2.70 & 2.55 & 1.82 & 2.16 & 1.85 & 5.75 & 8.87 & 4.13 & 3.66 & 3.72 & 2.31 \\
\hline$t_{1 / 2(\beta)}(\min )$ & 194.14 & 243.07 & 124.71 & 181.49 & 98.42 & 131.42 & 113.24 & 122.48 & 113.78 & 146.97 & 48.20 \\
\hline
\end{tabular}

$$
\begin{gathered}
O F_{\mathrm{B}-\mathrm{U}}=O F_{\mathrm{B}-\mathrm{U}\left(0-T_{0}\right)}+O F_{\mathrm{B}-\mathrm{U}\left(T_{0}-T\right)}=k_{\mathrm{p}}\left(\int_{0}^{T_{0}} x_{1} d t+\int_{T_{0}}^{T} x_{1} d t\right) \\
O F_{\mathrm{B}-\mathrm{T}}=O F_{\mathrm{B}-\mathrm{T}\left(0-T_{0}\right)}+O F_{\mathrm{B}-\mathrm{T}\left(T_{0}-T\right)}=k_{\mathrm{d}}\left(\int_{0}^{T_{0}} x_{1} d t+\int_{T_{0}}^{T} x_{1} d t\right)
\end{gathered}
$$

Where $O F_{\mathrm{B}-\mathrm{U}}$ represents the drug amount that was directly hydrolyzed in blood then eliminate into urine, $T_{0}$ is the infusion time, $T$ means the time point $T$ after infusion, $O F_{\mathrm{B}-\mathrm{T}}$ indicated drug amount that influxs into tissues from blood. Along with the drug penetration into tissues, the drug accumulated in tissues increased and the amount efflux into blood from tissues would not be an ignorable aspect. Equation 11 can be derived from the integration of Eq. 1.

$$
\left.x_{1}\right|_{T_{0}} ^{T}=-k_{\text {total }} \int_{T_{0}}^{T} c_{1} V_{1} d t+k_{1} \int_{T_{0}}^{T} x_{2} d t
$$

Where we define $O F_{\mathrm{T}-\mathrm{B}\left(T_{0}-T\right)}$ in following equation:

$$
O F_{\mathrm{T}-\mathrm{B}\left(T_{0}-T\right)}=k_{1} \int_{T_{0}}^{T} x_{2} d t
$$

Here, $O F_{\mathrm{T}-\mathrm{B}\left(T_{0}-T\right)}$ means drug amount efflux from tissues to blood. Finally, we can obtain the fraction that efflux from the tissues in Eq. 13, which was derived from Eqs. 11 and 12.

$$
O F_{\mathrm{TB}\left(T_{0}-T\right)}=V_{1}\left(c_{1(T)}-c_{1\left(T_{0}\right)}+k_{\text {total }} \cdot A U C_{1\left(T_{0}-T\right)}\right)
$$

Where $O F_{\mathrm{T}-\mathrm{B}\left(T_{0}-T\right)}$ referred to the amount that efflux from tissues into blood. The drug hydrolysis amount in blood and tissues can be compared and the relative contribution of blood and tissues can be evaluated according to formula 14 .

$$
M R=\frac{O F_{\mathrm{B}-\mathrm{U}}}{O F_{\mathrm{B}-\mathrm{T}}-O F_{\mathrm{T}-\mathrm{B}\left(T_{0}-T\right)}} \times 100 \%
$$

Data Analysis The area under the plasma concentration-time curve $(A U C)$ was calculated by the linear trapezoidal method. The plasma elimination half-life $\left(t_{1 / 2}\right)$ in alpha phase and beta phase were determined by least square method with AIC as criteria. $C_{\max }$ was expressed in actual value. Using Microsoft Excel software (Microsoft, Redmond, WA, U.S.A.), we completed the calculation of pharmacokinetic model parameters as well as the parameters for drug tissues influx and efflux.

\section{RESULTS}

Pharmacokinetic Result Two-compartment model was suitable for nafamostat pharmacokinetic description. The basic pharmacokinetic parameters for each subject were estimated and summarized in Table 1. As mentioned above, plasma con-

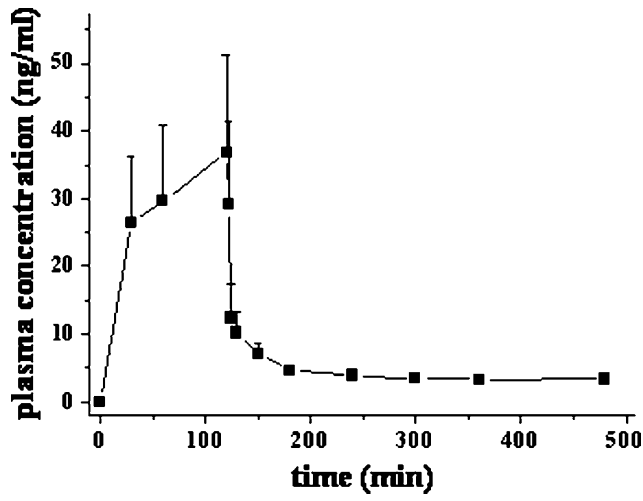

Fig. 2. Mean Plasma Concentration-Time Profile of Nafamostat Mesilate in 9 Healthy Chinese Volunteers after Constant Infusion Dripping at the Dose of $20 \mathrm{mg}$ for $2 \mathrm{~h}$

centration sharply declined with half-life about $3.7 \mathrm{~min}$ in alpha phase, however, relatively slow elimination was observed with about 147 min half-life in beta phase. The mean plasma concentration-time curve was illustrated in Fig. 2.

Global Estimation of Drug Influx into or Efflux from Tissues According to the method above, we predicted the amount of drug influx into and efflux from tissues. As the results shown, only about $20 \%$ drug given was hydrolyzed in blood. Accordingly, the rapid influx into peripheral tissues may mainly ascribe to the sharp decline of the plasma concentration, especially to the elimination alpha phase. Not all the drug influx into tissues was hydrolyzed in situ and about $30 \%$ of the drug penetrated into tissues efflux into blood again. The flux between tissues and blood keeps the blood and tissues concentration at a balance, which promotes the drug migrating to the site with higher hydrolysis capacity. Along with drug elimination, the drug efflux from tissues also played a more and more important role for plasma drug concentration, especially at the terminal beta-phase. The drug flow amount through three pathways within each $2 \mathrm{~h}$ was illustrated in Fig. 3, and all the results were summarized in Table 2.

\section{DISCUSSION}

Blood esterase activity was different depending on species and the rats may exhibit higher activity than the human, while human liver esterase activity may exhibit more. For the drugs with ester group and metabolism through hydrolysis, in rats, the blood esterase activity was high and may play a crucial role for drugs hydrolysis, while in human, the blood esterase may not be as powerful as rats and the tissue may give more contribution for drug hydrolysis. ${ }^{4)}$ The pharmaco- 


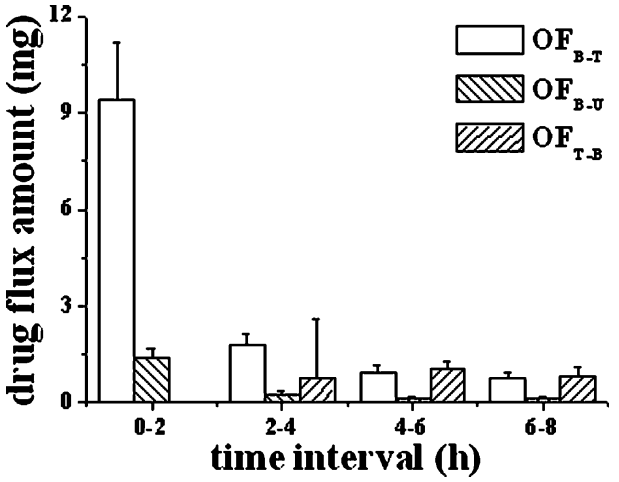

Fig. 3. Nafamostat Bidirectional Flow Amount between Tissue and Blood, and the Drug Direct Hydrolysis in Blood with $2 \mathrm{~h}$ Interval

$O F_{\mathrm{B}-\mathrm{T}}, O F_{\mathrm{T}-\mathrm{B}}$ and $O F_{\mathrm{B}-\mathrm{U}}$ represent the drug influx into, influx from tissues and direct hydrolysis in blood, respectively.

Table 2. The Estimated Parameters and Amount of Drug Flow between Tissue and Blood in 9 Healthy Volunteers after Intravenous Drip Infusion of $20 \mathrm{mg}$ Nafamostat Mesilate

\begin{tabular}{ccccccccc}
\hline \hline No. & $\begin{array}{c}V_{1} \\
(1)\end{array}$ & $\begin{array}{c}k_{\mathrm{p}} \\
\left(\mathrm{min}^{-1}\right)\end{array}$ & $\begin{array}{c}O F_{\mathrm{B}-\mathrm{U}} \\
(\mathrm{mg})\end{array}$ & $\begin{array}{c}k_{\mathrm{d}} \\
\left(\mathrm{min}^{-1}\right)\end{array}$ & $\begin{array}{r}O F_{\mathrm{B}-\mathrm{T}} \\
(\mathrm{mg})\end{array}$ & $\begin{array}{c}O F_{\mathrm{T}-\mathrm{B}} \\
(\mathrm{mg})\end{array}$ & $\begin{array}{c}M R \\
(\%)\end{array}$ & $\begin{array}{c}M_{\text {loss }} \\
(\mathrm{mg})\end{array}$ \\
\hline 1 & 66.17 & 0.03 & 1.6 & 0.40 & 11.17 & 2.57 & 19 & 2.65 \\
2 & 167.52 & 0.02 & 2.67 & 0.43 & 9.46 & 2.35 & 38 & 3.07 \\
3 & 84.6 & 0.02 & 1.56 & 0.30 & 9.63 & 2.17 & 21 & 3.83 \\
4 & 151.19 & 0.01 & 1.26 & 0.18 & 8.95 & 1.34 & 17 & 3.98 \\
5 & 61.5 & 0.05 & 1.45 & 0.48 & 14.58 & 4.16 & 14 & 0.98 \\
6 & 61.5 & 0.04 & 3.42 & 1.14 & 12.61 & 4.16 & 40 & 0.98 \\
7 & 90.48 & 0.03 & 2.99 & 0.72 & 11.87 & 3.51 & 36 & 1.5 \\
8 & 123.46 & 0.03 & 2.46 & 0.56 & 14.38 & 6.08 & 30 & 2.09 \\
9 & 49.33 & 0.04 & 2.69 & 0.94 & 11.61 & 3.24 & 32 & 1.79 \\
Mean & 95.08 & 0.03 & 2.23 & 0.57 & 11.58 & 3.29 & 27 & 2.32 \\
S.D. & 42.6 & 0.01 & 0.78 & 0.31 & 2.04 & 1.41 & 10 & 1.13 \\
\hline
\end{tabular}

$V_{1}$ referred to the apparent volume distribution. $k_{\mathrm{p}}$ and $k_{\mathrm{d}}$ referred to the drug hydrol ysis in blood and distribution into tissues rates, respectively. $O F_{\mathrm{B}-\mathrm{U}}, O F_{\mathrm{B}-\mathrm{T}}$ and $O F_{\mathrm{T}-\mathrm{B}}$ were the drug amount that direct hydrolysis in blood, influx into tissues and efflux from tissues, respectively. $M R$ indicated metabolic ratio between blood and tissues, which is calculated according to formula: $M R=O F_{\mathrm{B}-\mathrm{U}} /\left(O F_{\mathrm{B}-\mathrm{T}}-O F_{\mathrm{TB}(T-T)}\right) \times$ $100 \%$. $M_{\text {loss }}$ refers to the amount that cannot be balanced by our method, which was calculated according to the formula: $M_{\mathrm{loss}}=\operatorname{dose}-\left(O F_{\mathrm{B}-\mathrm{U}}+O F_{\mathrm{B}-\mathrm{T}}-O F_{\mathrm{T}-\mathrm{B}}\right)$.

kinetics may show species difference of the main hydrolysis sites. ${ }^{8)}$ Until now, no one has given a quantitative method to estimate the relative contribution of blood and tissue for these drugs hydrolysis. Based on our hypothesis that the drug that was directly hydrolyzed in blood was excreted into urine, we estimated the rate of blood hydrolysis. And in the initial phase of drug administration, the drug efflux from tissue into blood was ignorable comparing with the amount that flowed into tissue. Then we can estimate the rate that drug diffusion into tissue. Along with drug accumulating in tissue, and according to the mass balance, we also calculated the drug efflux from tissue. The net flow between blood and tissue represented the drug hydrolysis fraction by tissue esterase.

In clinical experiments, tissue distribution is important for drug evaluation, playing a fundamental role in their pharmacokinetic behavior and conditioning the pharmacological and toxicological responses. Although the importance of distribution is clear in clinical study, there are several methodological limitations to the development of drug tissue distribution studies. Among the methodological limitations, difficulties are involved in sampling, problems related to keeping viable systems, the heterogeneity of the process. ${ }^{12)}$ Recently, many techniques have been introduced in clinical tissue distribution study, including positron emission tomography (PET) and nuclear magnetic resonance spectroscopy (MRI). ${ }^{13,14}$ ) Thanks for these methods we can directly sample in specific tissue and subsequently analyze tissue samples. Besides, some strategies of tissue distribution have evolved from analysis based on compartment and physiological models to analyses based on spatial and fractal models. ${ }^{15,16)}$ In classical compartment models, we can give a global estimation of drug distribution regarding all the tissues or group of tissues as "peripheral compartments" without consideration of metabolism in the compartment. ${ }^{17)}$ For some drugs like nafamostat, sometimes due to transporter-mediated mechanism, they often accumulate largely in these high-perfusion tissues, which may exceed the blood concentration several times, ${ }^{18}$ ) such as liver and kidney. In the compartment theory, for these drugs, these tissues should also be classified into "peripheral compartments," because they are not uniform with the systematic circulation. Also, some of these high-perfusion organs often play a crucial role in drug metabolism. The drug diffusing into these tissues can disappear via two pathways, metabolism in tissues or efflux from tissues into blood again (as Fig. 1 indicated). In clinical experiments, due to tissue sampling difficulties, the tissue concentration cannot be directly quantified. Without the tissues concentration, the "peripheral compartment" elimination rate cannot be estimated just based on plasma concentration; the drug tissues distribution level also cannot get accurate evaluation. But at the point of mass balance, it is necessary to develop a method that can give a global estimation of the amount accumulation in tissues for this kind of drugs. In our study, according to nafamostat pharmacokinetic ability, we developed a method that can globally estimate the drug influx into and efflux from "peripheral compartment" to system circulation, without considering the specific concentration accumulated in tissues. Furthermore, based on the net flow between tissues and blood, we can globally evaluate the tissues distribution level and then calculate the hydrolysis portion in tissues.

As for this kind of drug, tissues were served as not only metabolism sites, but as huge "drug reservoir." Much of the drug accumulated in tissues fluxes into blood again and plays an important role for the drug plasma concentration-time profile, especially in terminal phase. As the Fig. 2 indicated, the relative fraction between efflux and influx become larger and larger along with drug excretion and the drug efflux from tissue maintain the plasma concentration at a low level for a long time. The slow efflux process can promote drug flowing from highly accumulated tissues to the effect site, just as reservoir for drug in body. Actually, for some drugs, although the plasma concentration is low, the pharmacological action can maintain for a long time partly due to the drug efflux from accumulated tissues.

Although we evaluated the drug fate at a global level and regarded all the tissues as a uniform compartment, much difference still exists between different tissues. The liver or kidney mainly served as drug hydrolysis part, and many other tissues may mainly serve as drug reservoir. The drug flow between tissues was a dynamic balance process through blood circulation. Knowing the main hydrolysis site, we could analyze the main type of esterase for nafamostat hydrolysis and make effective strategies to elongate its half-life, which is an 
important aspect for this kind of drug development.

Acknowledgment The National Science Foundation of China sponsored this research (No.30772609).

\section{REFERENCES}

1) Koshiyama Y., Kobori A., Ogihara M., Yokomoto Y., Ohtani K., Shimamura K., Iwaki M., Nippon Yakurigaku Zasshi, 90, 313-320 (1987).

2) Pereboom I. T., de Boer M. T., Porte R. J., Molenaar I. Q., Dig. Surg., 24, 282-287 (2007).

3) Yamashita Y., Ishiguro Y., Sano D., Kimura M., Fujita K., Yoshida T., Horiuchi C., Taguchi T., Matsuda H., Mikami Y., Tsukuda M., Auris Nasus Larynx, 34, 487-491 (2007).

4) Yamaori S., Fujiyama N., Kushihara M., Funahashi T., Kimura T., Yamamoto I., Sone T., Isobe M., Ohshima T., Matsumura K., Oda M., Watanabe K., Drug Metab. Pharmacokinet., 21, 147-155 (2006).

5) Yamaori S., Ukena E., Fujiyama N., Funahashi T., Kimura T., Yamamoto I., Ohshima T., Matsumura K., Oda M., Watanabe K., Xenobiotica, 37, 260-270 (2007)

6) Nanpo T., Ohtsuki T., Jin Y., Matsunaga K., Takahashi M., Shibuya
M., Sasaki H., Kurumi M., Clin. Rep., 18, 467-488 (1984).

7) Abe T., Kinoshita T., Matsuda J., Ogushi T., Kawasugi K., Yoshimura Y., Otomo M., Jpn. Pharmacol. Ther., 12, 65-88 (1984).

8) Minagawa T., Kohno Y., Suwa T., Tsuji A., Biochem. Pharmacol., 49, 1361-1365 (1995).

9) De Buck S. S., Mackie C. E., Expert Opin. Drug Metab. Toxicol., 3, $865-878$ (2007).

10) Price P. S., Conolly R. B., Chaisson C. F., Gross E. A., Young J. S., Mathis E. T., Tedder D. R., Crit. Rev. Toxicol., 33, 469-503 (2003).

11) Cao Y. G., Zhang M., Yu D., Shao J. P., Chen Y. C., Liu X. Q., Anal. Bioanal. Chem., 391, 1063-1071 (2008).

12) Lanao J. M., Fraile M. A., Curr. Pharm. Des., 11, 3829-3845 (2005).

13) Christensen J. D., Babb S. M., Cohen B. M., Renshaw P. F., Magn. Reson. Med., 39, 149-154 (1998).

14) Li Q., Sai Y., Kato Y., Muraoka H., Tamai I., Tsuji A., J. Pharm. Sci., 93, 262-272 (2004).

15) Macheras P., Pharm. Res., 13, 663-670 (1996).

16) Sung C., van Osdol W. W., Saga T., Neumann R. D., Dedrick R. L., Weinstein J. N., Cancer Res., 54, 2166-2175 (1994).

17) Hough L. B., Bagal A. A., Glick S. D., Methods Find. Exp. Clin. Pharmacol., 22, 77-81 (2000).

18) Shitara Y., Horie T., Sugiyama Y., Eur. J. Pharm. Sci., 27, 425- 426 (2006). 